\title{
A Small Quad-Band Monopole Antenna with Folded Strip Lines for WiMAX/WLAN and ITU Applications
}

\author{
Y. Zehforoosh, M. Rezvani \\ Department of Electrical Engineering, Urmia Branch, Islamic Azad University, Urmia, Iran \\ Young Researchers and Elite Club, Urmia Branch, Islamic Azad University, Urmia, Iran \\ yahsar.zehforoosh@gmail.com,mirhamed.rezvani@gmail.com
}

\begin{abstract}
In this article, a small Quad-Band microstrip patch antenna with folded strip lines for WiMAX/WLAN and ITU Applications is presented. This antenna consists eight symmetrical rectangular folded strip lines with 2 PIN diodes, ground plane and dimensions of $15 \times 20 \times 1.6 \mathrm{~mm}^{3}$. Using PIN diodes integrated within the antenna configuration, the antenna would be able to operate in two modes. The operational frequency bands of antenna are WLAN (2.4/5.2/5.8GHz), WiMAX (3.5/5.5GHz) and ITU-Region 1 allocation $(4.3 \mathrm{GHz})$ when diodes=on. In this design approach of antenna, omnidirectional radiation pattern and $S_{11}-10 d B$ bandwidths are obtained for all frequency bands. This antenna is fabricated on FR4 substrate with permittivity of 4.4 and loss tangent of 0.024 .
\end{abstract}

Index Terms - Microstrip patch antenna, Quad-Band, WiMAX, WLAN, ITU.

\section{INTRODUCTION}

Recently, the demand for the design of an antenna with triple or multiband operation has increased since such an antenna is vital for integrating more than one communication standards in a single compact system to effectively promote the portability of a modern personal communication system [1]. For this demand, the developed antenna must not only be with a triple/multiband operation but also have a simple structure, compact size, and easy integration with the circuit [1]. In modern wireless communication systems, multiband antenna has been playing a very important role for wireless service requirements. Wireless local area network (WLAN) and worldwide interoperability for microwave access (WiMAX) have been widely applied in mobile devices, such as handheld computers and intelligent phones [2]. Also many efforts in UWB antenna fields have been reported that more descriptions come in [3-11].

To design a multiband antenna for multimode wireless communication system, various methods have been explored [12-16]. A compact zigzag-shaped-slit rectangular microstrip patch antenna with circular defected ground structure (DGS) is designed for wireless applications [17]. A simple microstrip antenna for the radio frequency identification (RFID) applications and WLAN with two operating bands at 2.45 and $5.8 \mathrm{GHz}$ [18]. A triple-band metamaterial (MTM)-inspired antenna consists of two L-dumbbell-shaped unit cells, feed and partial ground plane for WLAN and WiMAX applications [19]. Compact metamaterial inspired triple band antenna for the frequency bands 2.4, 3.5 
and $5 \mathrm{GHz}[20]$ and also a low profile planar microstrip antenna is proposed to operate at lower WLAN (2.4 GHz) and WiMAX (3.5GHz) frequency bands [21]. Antenna with smaller dimensions, easy to design and fabricate, can be operate in two different performance frequency bands and more applications are other advantage of antennas.

In this paper a small Quad-Band planar monopole antenna for WLAN applications with coverage in all three frequency bands $(2.4 / 5.2 / 5.8 \mathrm{GHz})$ and WiMAX with coverage in two frequency bands $(3.5 / 5.5 \mathrm{GHz})$ is presented based on IEEE $802.11 \mathrm{~b} / \mathrm{g}$ and IEEE $802.11 \mathrm{a}$ standards and also $4.3 \mathrm{GHz}$ for ITU-Region1 allocation applications. This design with using two diodes can operate in two different modes, Antenna performance with Quad-Band frequency when diodes are turned on and the performance of antennas in Dual-Band frequency when diodes are turned off. This antenna with a simple design and the use of eight symmetrical rectangular folded strip lines is fabricated on FR4 substrate with small dimensions.

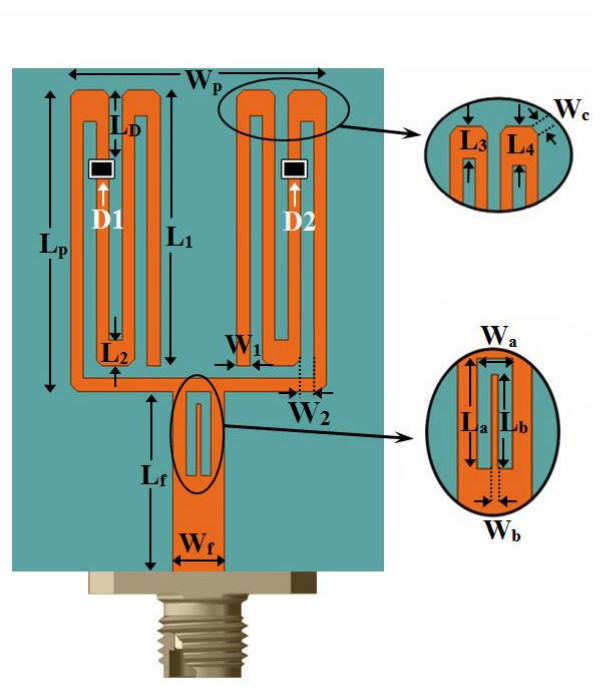

(a)

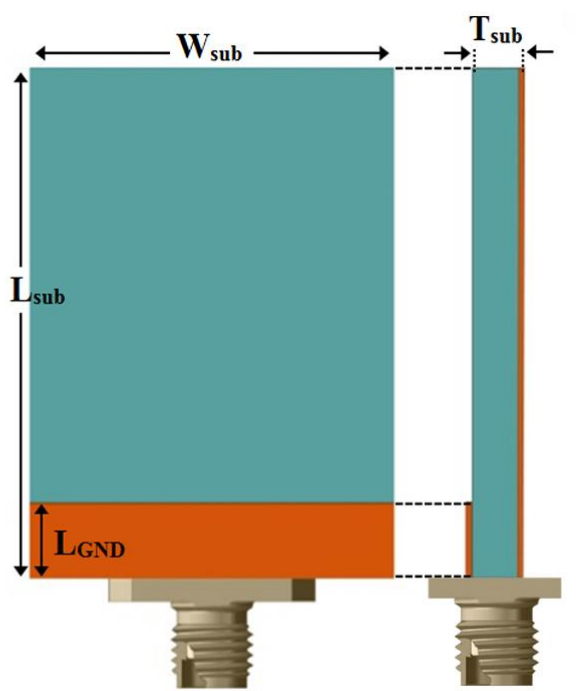

(b)

Fig. 1. (a) Top view and (b) bottom view of proposed antenna

\section{ANTENNA DESIGN}

Figure (1-a) shows top view of the designed antenna and Figure (1-b) shows its bottom view. This antenna is fabricated on the FR4 substrate with $\varepsilon_{\mathrm{r}}=4.4$, $\tan \delta=0.024$, thickness of $1.6 \mathrm{~mm}$ and dimensions of $15 \times 20 \mathrm{~mm}^{2}$. The radiation patch of this antenna is made of eight symmetrical rectangular folded strip lines where the operation of antenna increased by adding chamfer in corners. According to Figure (2) in the first step with using four symmetrical rectangular folded strip lines it is possible to design antenna with the same length and width. This step of the antenna which is presented in Figure (2-a) only covers two frequency bands. Second step is presented in Figure (2-b). This step has six symmetrical rectangular folded strip lines obtained by adding two strip lines with the same width and length to the step 1 . In this step, a frequency band is added to the antenna 
performance. In the third step presented as step 3 in Figure (2-c), it can be observed that finally by adding two other symmetrical rectangular folded strip lines to patch layer the antenna operate in four frequency bands for WiMAX, WLAN and ITU applications. Optimum dimensions of antenna are presented in Table 1.

Table 1. Optimum dimensions of antenna

\begin{tabular}{||c|c|c|c||}
\hline Parameter & Value & Parameter & Value \\
\hline $\mathrm{W}_{\text {sub }}$ & $15 \mathrm{~mm}$ & $\mathrm{~L}_{3}$ & $1 \mathrm{~mm}$ \\
\hline $\mathrm{L}_{\text {sub }}$ & $20 \mathrm{~mm}$ & $\mathrm{~L}_{4}$ & $1.25 \mathrm{~mm}$ \\
\hline $\mathrm{T}_{\text {sub }}$ & $1.6 \mathrm{~mm}$ & $\mathrm{~L}_{\mathrm{a}}$ & $3.3 \mathrm{~mm}$ \\
\hline $\mathrm{W}_{\mathrm{f}}$ & $2 \mathrm{~mm}$ & $\mathrm{~L}_{\mathrm{b}}$ & $2.8 \mathrm{~mm}$ \\
\hline $\mathrm{L}_{\mathrm{f}}$ & $7.2 \mathrm{~mm}$ & $\mathrm{~L}_{\mathrm{D}}$ & $3 \mathrm{~mm}$ \\
\hline $\mathrm{W}_{\mathrm{p}}$ & $10 \mathrm{~mm}$ & $\mathrm{~W}_{1}$ & $0.5 \mathrm{~mm}$ \\
\hline $\mathrm{L}_{\mathrm{p}}$ & $11.8 \mathrm{~mm}$ & $\mathrm{~W}_{2}$ & $0.5 \mathrm{~mm}$ \\
\hline $\mathrm{L}_{\mathrm{GND}}$ & $3 \mathrm{~mm}$ & $\mathrm{~W}_{\mathrm{a}}$ & $1 \mathrm{~mm}$ \\
\hline $\mathrm{L}_{1}$ & $10.8 \mathrm{~mm}$ & $\mathrm{~W}_{\mathrm{b}}$ & $0.2 \mathrm{~mm}$ \\
\hline $\mathrm{L}_{2}$ & $1 \mathrm{~mm}$ & $\mathrm{~W}_{\mathrm{c}}$ & $0.35 \mathrm{~mm}$ \\
\hline
\end{tabular}

Using two diodes at the distance of $\mathrm{L}_{\mathrm{D}}$ in the second strip lines of the patch it is possible to work in two frequency modes, The performance in the frequency bands $3.5 / 5.5 \mathrm{GHz}$ for WiMAX and the performance in the frequency band $\mathbf{5 . 8 G H z}$ for third band of WLAN when the diodes are off; also the frequency coverage of $2.4 / 5.2 / 5.8 \mathrm{GHz}$ for WLAN and $4.3 \mathrm{GHz}$ for ITU-Region1 allocation when diodes are on.

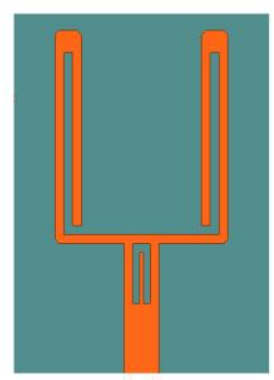

(a)

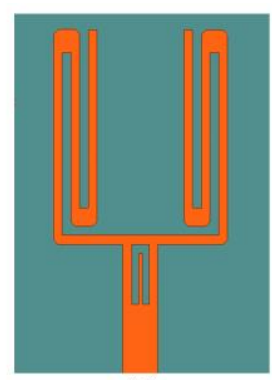

(b)

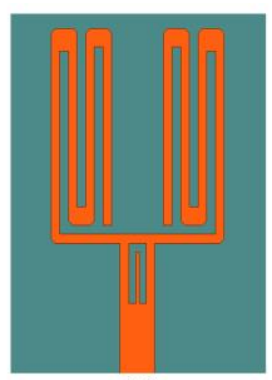

(c)

Fig. 2. Antenna designing procedure, (a) step 1, (b) step 2 and (c) step 3

The radiation patch of the antenna is fed by $50 \Omega$ microstrip feeding line. In the fed line an inverted $\mathrm{U}$ shape slot is added to better impedance matching. The ground plane of this antenna is designed with the length $\mathrm{L}_{\mathrm{g}}=3 \mathrm{~mm}$ with the same width of the substrate $\left(\mathrm{W}_{\text {sub }}\right.$ ). Figure (3-a) presents the 3 dimensional view of the antenna and Figure (3-b) presents the top and bottom views of the fabricated antenna. 


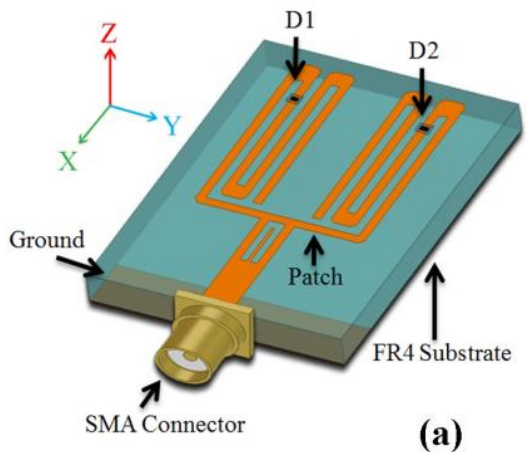

(a)

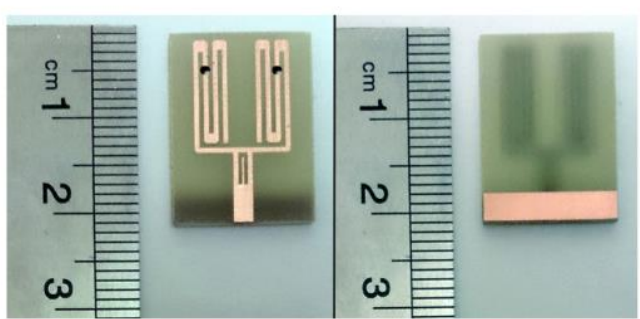

(b)

Fig. 3. (a) Side view of the proposed antenna and (b) top and bottom view of fabricated antenna

\section{RESULTS AND DISCUSSIONS}

Figure (4) shows reflection coefficient plot steps 1, 2 and 3 of the proposed antenna. Figure (5) shows the comparison of reflection coefficient for the simulated mode of the HFSS software and measured mode in the laboratory for state $D_{1} \& D_{2}=$ off. Figure (6) presents the comparison of reflection coefficient for simulated and measurement state $\mathrm{D}_{1} \& \mathrm{D}_{2}=\mathrm{on}$. These results represent the low tolerances among the simulated and the measured mode in the laboratory. The simulated gain of the proposed antenna is shown in Figure (7).

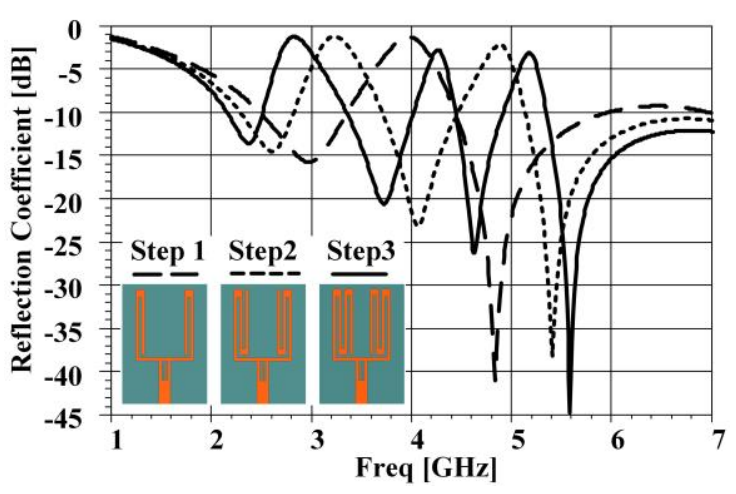

Fig. 4. Reflection coefficient plot step 1, step 2 and step 3 of proposed antennas

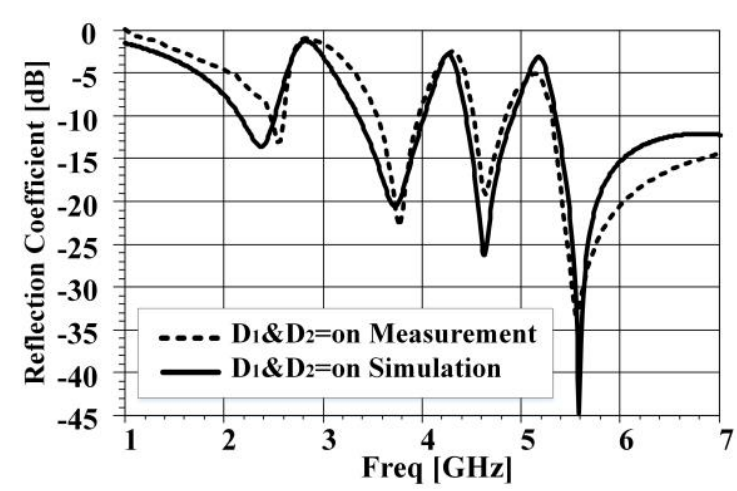

Fig. 6. Measured and simulated reflection coefficient for $\mathrm{D}_{1} \& \mathrm{D}_{2}=$ on

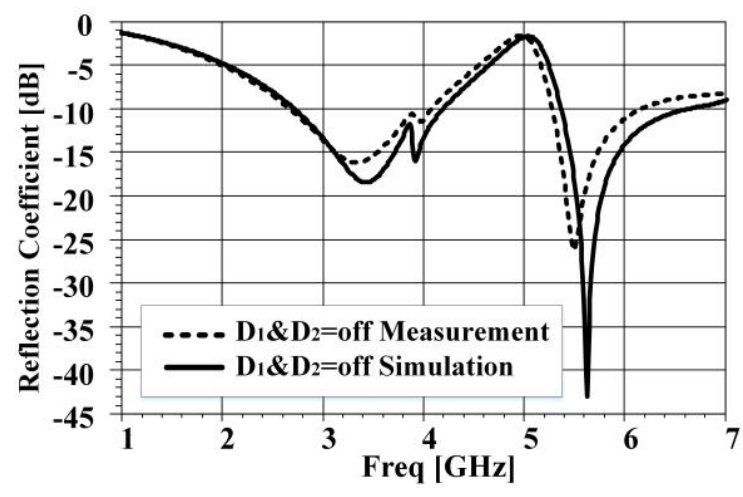

Fig. 5. Measured and simulated reflection coefficient for $\mathrm{D}_{1} \& \mathrm{D}_{2}=$ off

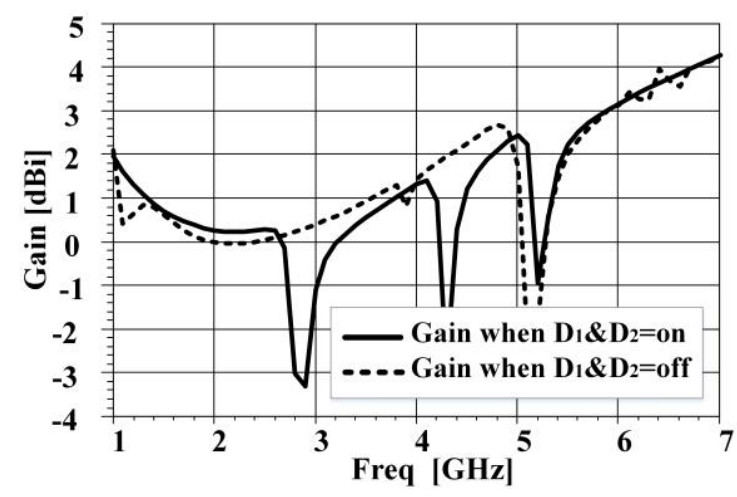

Fig. 7. Simulated gain of proposed antenna 
The radiation pattern in $\varphi=0^{\circ} \& 90^{\circ}$ (H-plane) and $\theta=0^{\circ} \& 90^{\circ}$ (E-plane) for $3.5 \mathrm{GHz}$ and $5.5 \mathrm{GHz}$ frequency bands and $\mathrm{D}_{1} \& \mathrm{D}_{2}=$ off in Figure (8) indicate the omnidirectionality if the antenna. Also, the simulated $\mathrm{H}$-plane and E-plane radiation patterns for $2.4 \mathrm{GHz}, 3.5 \mathrm{GHz}, 4.3 \mathrm{GHz}$ and $5.5 \mathrm{GHz}$ are shown in Figure (9). These figures illustrate both, co-polarization and cross polarization. Figure (10) represents currents distribution of the antenna for four frequency bands when the diodes are on.

Table 2 presents the comparison between the designed antenna in this article and references [17] to [21]. This comparison presents the smallest dimensions and most applications of the antenna designed in this paper compared to the mentioned papers.
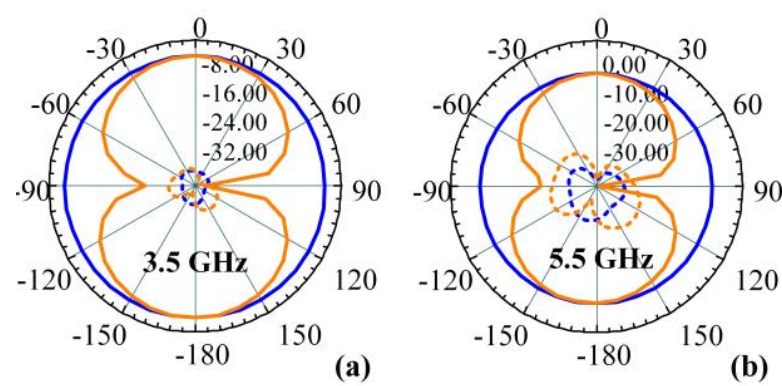

(a)

(b)

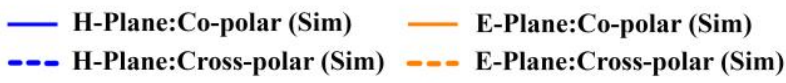

Fig. 8. Simulated radiation pattern of the proposed antenna for $D_{1} \& D_{2}=$ off

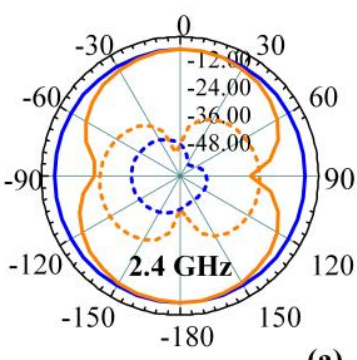

(a)

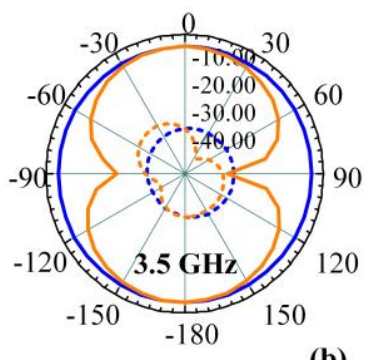

(b)

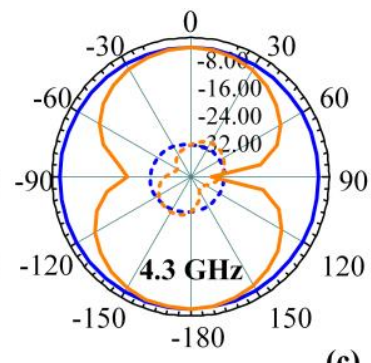

(c)

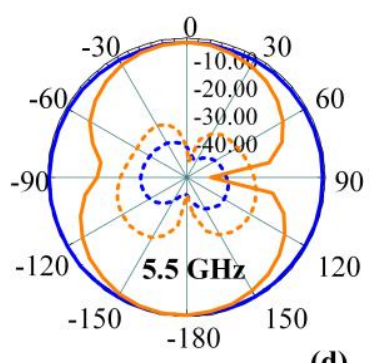

(d)

$\begin{array}{lll}\text { - H-Plane:Co-polar (Sim) } & \text { E-Plane:Co-polar (Sim) } \\ --- \text { H-Plane:Cross-polar (Sim) } & --- & \text { E-Plane:Cross-polar (Sim) }\end{array}$

Fig. 9. Simulated radiation pattern of the proposed antenna for $D_{1} \& D_{2}=o n$

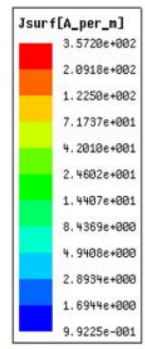

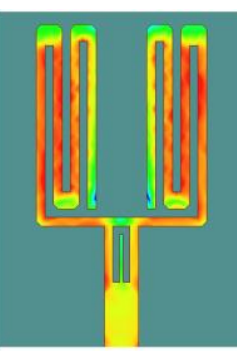

(a)

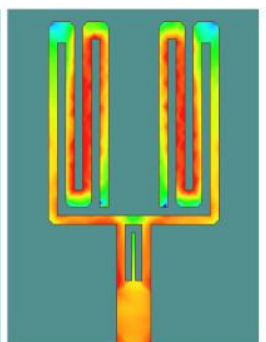

(b)

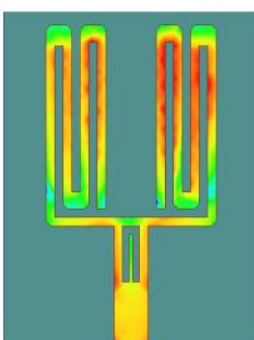

(c)

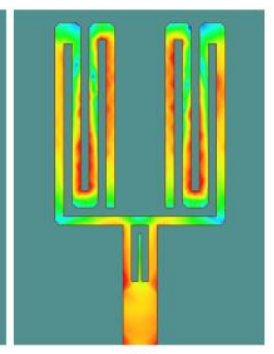

(d)

Fig. 10. Currents distribution of the antenna for (a) $2.4 \mathrm{GHz}$, (b) $3.5 \mathrm{GHz}$, (c) $4.3 \mathrm{GHz}$ and (d) $5.5 \mathrm{GHz}$ 
Table 2. Comparison between antennas

\begin{tabular}{|c|c|c|c|c|}
\hline Ref & Applications & Fc [GHz] & Dimensions $\left(\mathrm{mm}^{2}\right)$ & $\begin{array}{c}\text { Total area occupied } \\
\text { by the antenna }\left(\mathrm{mm}^{2}\right)\end{array}$ \\
\hline$[17] 2015$ & WLAN / WiMAX & $2.4 / 3.5 / 5.2$ & $40 \times 28$ & 1120 \\
\hline$[18] 2015$ & RFID / WLAN & $2.45 / 5.8$ & $28.2 \times 36.7$ & 1034.94 \\
\hline$[19] 2015$ & WLAN / WiMAX & $2.4 / 3 / 5.7$ & $30 \times 30$ & 900 \\
\hline$[20] 2015$ & WLAN / WiMAX & $2.4 / 3.5 / 5$ & $27 \times 25$ & 675 \\
\hline$[21] 2015$ & WLAN / WiMAX & $2.4 / 3.5$ & $10 \times 40$ & 400 \\
\hline This Work & WLAN / WiMAX / ITU & $2.4 / 3.5 / 4.3 / 5.5$ & $15 \times 20$ & 300 \\
\hline
\end{tabular}

\section{CONCLUSION}

In this paper a small Quad-Band monopole antenna with using eight symmetrical rectangular folded strip lines is analyzed for WiMAX/WLAN and ITU applications. In this antenna using two PIN diodes in antenna structure, two modes of operation were obtained. By turning the diodes off the Dual-Band frequency antenna with $3.5 / 5.5 \mathrm{GHz}$ for WiMAX application and single band frequency of $5.8 \mathrm{GHz}$ covers WLAN that the results of reflection coefficient were studied. Also be turning the diodes on, the antenna can be used for WiMAX applications with frequencies $3.5 / 5.5 \mathrm{GHz}$, WLAN with frequencies $2.4 / 5.2 / 5.8 \mathrm{GHz}$ and ITU-Region1 allocation with the frequency $4.3 \mathrm{GHz}$ that the results of reflection coefficient are presented for this mode. The advantages of this antenna include the simultaneous function of WiMAX/WLAN and ITU with ability to operate in two different modes through the diodes, small dimensions and simple design and fabrication.

\section{REFERENCES}

[1] Wen-Chung Liu, Chao-Ming Wu, and Yang Dai, "Design of Triple-Frequency Microstrip-Fed Monopole Antenna Using Defected Ground Structure," IEEE Transactions on Antennas and Propagation, Vol. 59, No. 7, pp. 2457-2463, July 2011.

[2] Payam Beigi, Javad Nourinia, Yashar Zehforoosh, and Bahman Mohammadi, "A Compact Novel CPW-Fed Antenna with Square Spiral-Patch for Multiband Applications," Microwave and Optical Technology Letters, Vol. 57, No. 1, pp. 111-115, January 2015.

[3] Z. Badamchi, and Y. Zehforoosh, "Switchable Single/Dual Band Filtering UWB Antenna Using Parasitic Element and T-Shaped Stub Wave Cancellers," Microwave and Optical Technology Letters, Vol. 57, No. 12, pp. 2946-2950, December 2015.

[4] Mehdi Sefidi, Yashar Zehforoosh, and Shahram Moradi, "A Novel CPW-Fed Antenna with Dual Band-Notche Charectrestics for UWB Applications,” Microwave and Optical Technology Letters, Vol. 57, No. 10, pp. 2391-2394, October 2015.

[5] Amir Siahcheshm, Javad Nourinia, Yashar Zehforoosh, and Bahman Mohammadi, "A Compact Modified Triangular CPW-Fed Antenna with Multioctave Bandwidth,” Microwave and Optical Technology Letters, Vol. 57, No. 1, pp. 6972, January 2015.

[6] Yashar Zehforoosh, and Tohid Sedghi, "A CPW-Fed Printed Antenna with Band-Notched Function Using an MShaped Slot," Microwave and Optical Technology Letters, Vol. 56, No. 5, pp. 1088-1092, May 2014.

[7] M. Sefidi, Y. Zehforoosh, and S. Moradi, "A Novel Monopole Antenna for Wireless Communication Systems and UWB Application,” Microwave and Optical Technology Letters, Vol. 55, No. 8, pp. 1856-1860, August 2013.

[8] R. A. Sadeghzadeh, Y. Zehforoosh, and N. Mirmotahhary. "Ultra-Wideband Monopole Antenna with Modified Triangular Patch,” Microwave and Optical Technology Letters, Vol. 53, No. 8, pp. 1752-1756, August 2011.

[9] M. Naser-Moghadasi, G. R. Dadashzadeh, M. Abdollahvand, Y. Zehforoosh, and B. S. Virdee, "Planar Triangular Monopole Antenna with Multioctave Bandwidth,” Microwave and Optical Technology Letters, Vol. 53, No. 1, pp. 1014, January 2011. 
[10] Vorya Waladi, Nooshin Mohammadi, Yashar Zehforoosh, Asieh Habashi, and Javad Nourinia, "A Novel Modified Star-Triangular Fractal (MSTF) Monopole Antenna for Super-Wideband Applications," IEEE Antennas and Wireless Propagation Letters, Vol. 12, pp. 651-654, 2013.

[11] Y. Zehforoosh, M. Naser-Moghadasi, R. A. Sadeghzadeh and Ch. Ghobadi, "Miniature monopole fractal antenna with inscribed arrowhead cuts for UWB applications,” IEICE Electron. Exp. Vol. 9, No. 24, pp. 1855-1860, 2012.

[12] Huiqing Zhai, Qiqiang Gao, Changhong Liang, Rongdao Yu, and Sheng Liu, "A Dual-Band High-Gain Base-Station Antenna for WLAN and WiMAX Applications," IEEE Antennas and Wireless Propagation Letters, Vol. 13, pp. 876879, 2014.

[13] S. Risco, J. Anguera, A. Andújar, A. Pérez, and C. Puente, "Coupled Monopole Antenna Design for Multiband Handset Devices,” Microwave and Optical Technology Letters, Vol. 52, no. 10, pp.359-364, Feb. 2010.

[14] C. Puente, J. Anguera, C. Borja, and J. Soler, "Fractal-Shaped Antennas and their Application to GSM 900/1800," The Journal of the Institution of British Telecommunications Engineers. vol. 2, Part. 3, July-Set. 2001.

[15] J. M. J. W. Jayasinghe, J. Anguera, and D.N. Uduwawala, "A Simple Design of Multi Band Microstrip Patch Antennas Robust to Fabrication Tolerances for GSM, UMTS, LTE, and Bluetooth Applications by Using Genetic Algorithm Optimization" Progress In Electromagnetics Research M, Vol. 27, pp. 255-269, 2012.

[16] J. Anguera, J.P. Daniel, C. J. Mumbrú, C. Puente, T. Leduc, K. Sayegrih, and P. Van Roy, "Metallized Foams for Antenna Design: Application to Fractal-Shaped Sierpinski-Carpet Monopole", Progress In Electromagnetics, Vol. 104, pp. 239-251, 2010.

[17] B. R. Sanjeeva Reddy, and D. Vakula, "Compact Zigzag-Shaped-Slit Microstrip Antenna with Circular Defected Ground Structure for Wireless Applications," IEEE Antennas and Wireless Propagation Letters, Vol. 14, pp. 678-681, 2015.

[18] Radouane Karli, Hassan Ammor, "Rectangular Patch Antenna for Dual-Band RFID and WLAN Applications," Wireless Personal Communications, Vol. 83, Issue. 2, pp. 995-1007, February 2015.

[19] Sameer Kumar Sharma, Jai Deep Mulchandani, Devvrat Gupta, Raghvendra Kumar Chaudhary, "Triple-Band Metamaterial-Inspired Antenna Using FDTD Technique for WLAN/WiMAX Applications," International Journal of RF and Microwave Computer-Aided Engineering, Vol. 25, No. 8, pp. 688-695, August 2015.

[20] Rajeshkumar V, Raghavan S, "A Compact Metamaterial Inspired Triple Band Antenna for Reconfigurable WLAN/WiMAX Applications," International Journal of Electronics and Communications (AEÜ), Vol. 69, Issue. 1, pp. 274-280, January 2015.

[21] Jagannath Malik, Amalendu Patnaik, and M. V. Kartikeyan, "A Compact Dual-Band Antenna with Omnidirectional Radiation Pattern,” IEEE Antennas and Wireless Propagation Letters, Vol. 14, pp. 503-506, 2015. 